\title{
Considerations in adopting a culturally relevant diabetes health education programme: An Indonesian example
}

\author{
Hema Malini, MNurs, BscNurs a,b,*, \\ Beverley Copnell, PhD, BAppSc, RN ${ }^{\mathrm{b}, 1}$, \\ Cheryle Moss, PhD, BAppSc, MSc, RN ${ }^{c, 2}$
}

\author{
a Faculty of Nursing, University of Andalas, West Sumatera, Indonesia \\ b School of Nursing and Midwifery, Monash University, Clayton Campus, Building 13C, Wellington Road, \\ Clayton, VIC 3168, Australia \\ c Research \& Practice Development School of Nursing and Midwifery, Monash University, Clayton Campus, \\ Building 13C, Wellington Road, Clayton, VIC 3168, Australia
}

Received 5 February 2014; received in revised form 20 October 2015; accepted 5 November 2015

\section{KEYWORDS}

Health education;

Diabetes;

Indonesian culture;

X-PERT;

DESMOND;

DAFNE

\begin{abstract}
Summary Confronted with data about the rising incidence of diabetes in Indonesia, and the recognition that no national programmes for diabetes education are in place, we conducted a search to identify effective western models of health education that could be considered for implementation in Indonesia. In this paper we report on the findings from the search, and share cultural considerations that would need to be applied if these programmes were adopted for use in Indonesia. We conclude that three structured education programmes, X-PERT, DESMOND and DAFNE, have been shown to be effective in a range of western settings and that these could be adapted for use in Indonesian contexts.

(c) 2015 Australian College of Nursing Ltd. Published by Elsevier Ltd.
\end{abstract}

\footnotetext{
* Corresponding author at: Faculty of Nursing, University of Andalas Padang, West Sumatera, Indonesia. Tel.: +62 751 779233; fax: +62 751779235

E-mail addresses: hema.malini@monash.edu, hema.maliniyusuf@gmail.com (H. Malini), beverley.copnell@monash.edu (B. Copnell), cheryle.moss@monash.edu (C. Moss).

1 Tel.: +61 39905 4836; fax: +6139905 4837.

2 Tel.: +61 39905 3469; fax: +6139905 4837 .
}

\section{Introduction}

Effective health education programmes and strategies can result in improved health outcomes, particularly through assisting people to acquire more knowledge and skills (Glanz, Rimmer, \& Viswanath, 2008). Worldwide there is a need for effective models of health education to take into account best evidence and to be culturally appropriate for the individual context. It is important that models of health education be applied as interventions 
in specific high incidence chronic diseases that affect global health, and that these programmes can be transferred between western and developing countries. We are particularly interested in diabetes and the Indonesian context. In this paper, we report findings in relation to several structured health education programmes for people with diabetes that have been employed successfully in western countries. We then consider whether these programmes could be applied in the Indonesian context.

In 2013, the number of people worldwide with diabetes was 382 million and close to half of this number, around 175 million were unaware of their disease. The number of people with diabetes, especially diabetes type 2, is predicted to increase by 55\% to 592 million by 2035 (IDF, 2013). Moreover, the International Diabetes Federation (IDF) stated that $80 \%$ of people with diabetes currently live in low and middle income countries (IDF, 2013).

It is well established that people with diabetes who live in developing countries are less likely to have specific knowledge and skill in diabetes self-management in comparison to their western counterparts. Many learn about diabetes and self-management from a variety of sources with varying credibility (WHO, 2011). The World Health Organisation (WHO) has made recommendations for global adoption, one of which is that countries develop a collaborative programme of health education for people with diabetes (WHO, 2011). However, in developing countries, health education programmes using structured sessions for groups of patients or communities are rare. Most diabetes education is delivered one-to-one between a patient and doctor and in an unstructured fashion (Widyahening \& Soewondo, 2012). Follow up sessions are uncommon due to the imbalance between patient numbers and the limited supply of qualified health professionals. Many people with diabetes find that education services mostly focus on medication control and less on providing knowledge and skills around diabetes management (Neraca, 2013). By contrast, in developed countries such as Australia, the United Kingdom (UK) and the United States (US), diabetes services focus on patient self-management education programmes based on a patient-centred approach (Department of Health, 2005; NDEP, 2011; NDSS, 2014). The programmes are delivered in a more structured fashion and follow up sessions occur more regularly. Programmes such as the National Diabetes Services Scheme (NDDS) in Australia, the National Diabetes Education Program in the UK and the National Diabetes Prevention Program (NDPP) in the US provide diabetes services that not only focus on medication but also on education to promote selfmanagement.

While evidence shows that effective self-management education programmes based on a patient-centred approach are effective in improving clinical and psychosocial outcomes in both the short- and long-term (Deakin, Cade, Williams, \& Greenwood, 2006), the application of structured health education programmes does not show the same result in developing countries. In a country such as Indonesia, the approach to diabetes education differs in that it does not focus on prevention and control.

\subsection{Profile and burden of diabetes in Indonesia}

In Indonesia, government statistics do not differentiate between people with diabetes type 1 and those with type 2 ; thus, the health needs of this group are considered as a whole. Currently, Indonesia is ranked 7th in the world for the number of people with diabetes (IDF, 2013). In 2013 the prevalence of diabetes in Indonesia was 5.55\% of the total adult population (154 million), with 8.5 million cases (IDF, 2013). It is predicted by 2035 this number will reach 14.1 million. Of the total number of adults with diabetes, $41 \%$ have been diagnosed with the disease but have not received treatment, $39 \%$ have received treatment, and only $1 \%$ take regular medication (Balitbang Depkes RI, 2013; IDF, 2013). In 2013, the Indonesian government in cooperation with a pharmaceutical company introduced a blueprint to improve diabetes outcomes in the country (Kementrian, 2014). The programme encouraged various elements of the community to work together to combat and reduce the impact of diabetes. One of the key points in this blueprint is improving the knowledge and skill of people with diabetes by providing them with health information. Unfortunately, due to the lack of qualified human resources to perform a structured diabetes education programme, the information was delivered in a traditional way, in which health professionals meet patients and deliver insufficient information focusing largely on medication control.

Primary health services in Indonesia are mostly delivered through community health centres known as Puskesmas (Kementrian, 2004). Puskesmas have several functions as both public health and community centres, providing primary health care for individuals and groups. Indonesia has 9005 Puskesmas with a ratio of 3.79 per 100,000 people (Kementrian, 2012). In 2010, there were 255,563 health professionals working in Puskesmas: nurses $(78,215)$, doctors $(14,934)$, dieticians $(7565)$ and midwives $(83,222)$ (Kementrian, 2012). Of that number, around half $(50.64 \%)$ had received staff development training specific to the setting (Kementrian, 2012). Puskesmas provide several programmes in order to support the goal of a healthy population. The most common programmes include health promotion; environmental health; nutrition improvement; the prevention and eradication of communicable diseases; maternal, child and family health; and balai pengobatan (basic medication) (Kementrian, 2004).

In terms of diagnosing patients with diabetes, $82 \%$ of Puskesmas can provide this service; however, capacity for treatment, detection and management of complications remains limited (Widyahening \& Soewondo, 2012). Health education programmes are generally focused on limited topics such as infectious and tropical diseases (Kementrian, 2011). Health information about diabetes and its management is rarely provided in Puskesmas as diabetes education training is not available for most health professionals due to limited funding (Kementrian, 2011). As a consequence, health education is conducted by health professionals as part of their daily job without a structured programme and with no clear objectives and goals (Soewondo, Ferrario, \& Tahapary, 2013). 


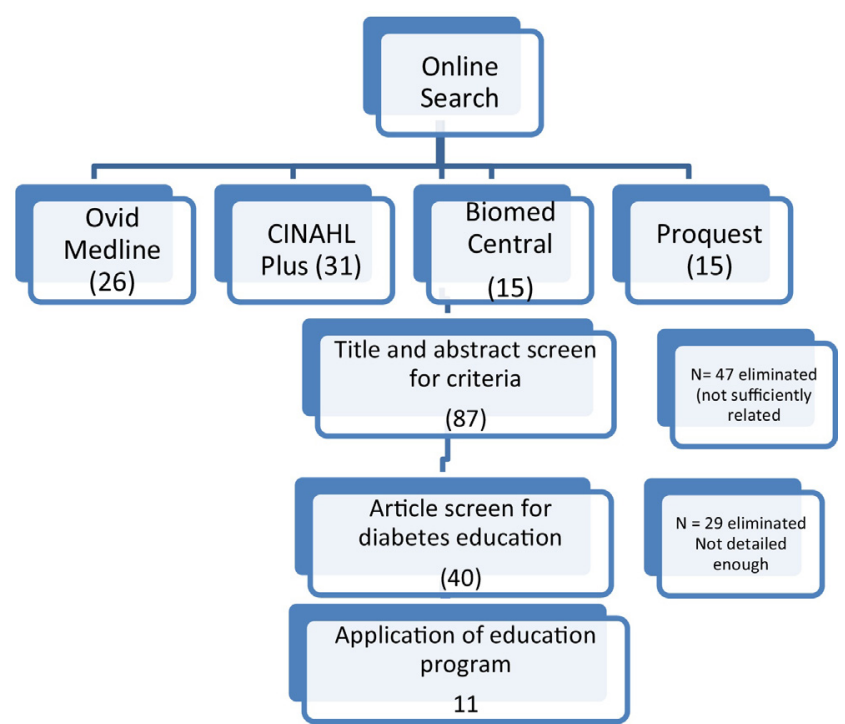

Figure 1 Search strategy.

\subsection{Aims}

The aim of this paper is to explore some considerations in applying a western validated model of diabetes education to the cultural context of a developing country, using Indonesia as a sample case. To achieve this, we addressed the following questions: (1) what is the evidence regarding the relevance of structured education models; (2) what structured education programmes for diabetes have evidence of success in western contexts and could be applied appropriately in a developing country such as Indonesia?

\subsection{Search methods}

A systematic search of literature was undertaken in consultation with a medicine, nursing and health science librarian, using the electronic databases EBSCOHost/CINAHL Plus, Ovid MEDLINE, ProQuest and Biomed Central. The search terms used were: health education; diabetes education programme; and patient education. These terms were used in order to retrieve peer-reviewed research, systematic reviews and guidelines on established diabetes education programmes. Research articles were included if they provided information on the content, structure or implementation of diabetes education programmes. Articles were excluded if they presented global data that did not directly link to the implementation of a diabetes education programme. The search retrieved 11 articles: seven studies related to the implementation of the education programme and 4 articles related to general information of structured education programme. The steps of the search strategy are shown in Fig. 1.

\section{Results}

\subsection{Structured education programmes}

Structured health education programmes are a specific form of communication that aim to improve the health knowledge and self-management skills of people with or who

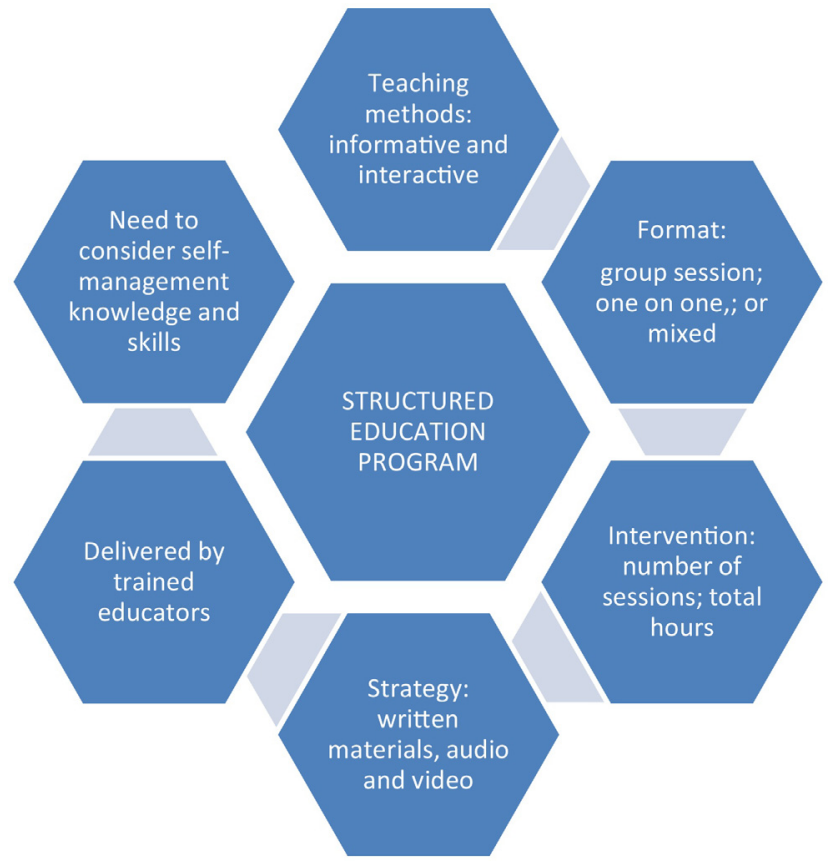

Figure 2 The basic principles of structured education programmes (Fan \& Sidani, 2009; Jarvis et al., 2010; NICE, 2003).

are likely to have chronic diseases (WHO, 1998). Structured health education programmes are delivered using a variety of techniques (information brochures, pamphlets, audio visual presentations and in person coaching) to influence the health behaviours of people at any level (individuals, groups or community wide) (WHO, 1998). Structured health education programmes can be conducted and applied to any health level and situation, from healthy people to those with certain diseases. For healthy people, the health knowledge and skills that they gain from health education programmes will be helpful in maintaining their health. For people with certain diseases, health information will be valuable in order to better deal with and self-manage their health status (Glanz \& Schwartz, 2008).

Evidence suggests that people with diabetes have to predominantly manage their own condition on a daily basis, and this can be achieved by having access to a structured education programme that provides education and self-management skills (Fan \& Sidani, 2009; Jarvis, Skinner, Carey, \& Davies, 2010). A structured education programme is "... a planned and graded programme that is comprehensive in scope, flexible in content, responsive to an individual's clinical and psychological needs, and adaptable to his or her educational and cultural background" (Department of Health, 2005). Structured education programmes are generally characterised by several principles: the teaching methods used in the programmes; the strategies used to convey the information; the format of the programmes between one to one or group or mixed sessions; the number and durations of the programmes (Fan \& Sidani, 2009; Jarvis et al., 2010). Additional characteristics include the programmes should be delivered by trained educators; have specific aim and learning objectives; and support the self-management knowledge and skills (NICE, 2003). The characteristics are shown in Fig. 2 (Fan \& Sidani, 2009; Jarvis et al., 2010; NICE, 2003). 


\begin{tabular}{|c|c|c|c|c|}
\hline NAME OF PROGRAM & Teaching Methods & Strategy & Format and Intervention & Outcome measures \\
\hline X-PERT & $\begin{array}{l}\text { Empowerment } \\
\text { approach and } \\
\text { discovery learning }\end{array}$ & $\begin{array}{l}\text { Mixed approach: } \\
\text { written and } \\
\text { teaching media }\end{array}$ & $\begin{array}{l}6 \text { week group education } \\
\text { program } \\
\text { Each session lasting for } 2.5 \\
\text { hours } \\
\text { Educators attend a } \\
\text { training course about } \\
\text { practical and knowledge } \\
\text { Assessments }\end{array}$ & $\begin{array}{l}\text { Improvement in body weight } \\
\text { \& diabetes control, reduced } \\
\text { diabetes medication, } \\
\text { increased skill to manage } \\
\text { diabetes, lifestyle, lower blood } \\
\text { pressure \& lower cholesterol }\end{array}$ \\
\hline $\begin{array}{l}\text { DESMOND (Diabetes } \\
\text { Education \& Self- } \\
\text { Management for } \\
\text { ongoing \& Newly } \\
\text { Diagnosed) }\end{array}$ & $\begin{array}{l}\text { Psychological } \\
\text { theory learning }\end{array}$ & $\begin{array}{l}\text { Non-didactic and } \\
\text { interactive } \\
\text { approach using } \\
\text { module }\end{array}$ & $\begin{array}{l}\text { Group education in } 3 \\
\text { formats: } 1 \text { day, } 2 \text { half days, } \\
\text { three } 2 \text { hour sessions } \\
\text { Educators: mixture of } \\
\text { dietitians \& practice } \\
\text { nurses-have } 2 \text { days } \\
\text { training prior to program }\end{array}$ & $\begin{array}{l}\text { Quality of Life (physical, } \\
\text { physiological, social \& } \\
\text { environmental) } \\
\text { Metabolic Control (HBA1c) } \\
\text { after three months, key points } \\
\text { of measures is in key illnesses } \\
\text { \& the patient's self- beliefs }\end{array}$ \\
\hline DAFNE & $\begin{array}{l}\text { Information based } \\
\text { on self-efficacy } \\
\text { approach }\end{array}$ & $\begin{array}{l}\text { Written } \\
\text { information and } \\
\text { Verbal persuasion, } \\
\text { simulation }\end{array}$ & $\begin{array}{l}\text { Five day session } \\
\text { Focus on nutrition, insulin } \\
\text { adjustment for daily life } \\
\text { situation }\end{array}$ & $\begin{array}{l}\text { Self-monitoring blood glucose } \\
\text { (SMBG), Insulin adjustment }\end{array}$ \\
\hline
\end{tabular}

Figure 3 The description of X-PERT, DESMOND and DAFNE as structured diabetes education programme.

\subsection{Existing structured diabetes education programmes}

In this section, the evidence related to the application of structured education programmes (X-PERT, DESMOND, and DAFNE) through several studies is presented. The evidence shows the effectiveness of the programmes in improving the clinical outcomes and the perception and experience of people with diabetes who were involved in them. There are three well established diabetes education programmes that have been implemented in the UK and Australia: X-PERT, DESMOND and DAFNE. A general description of these three programmes is presented in Fig. 3.

The effectiveness of these three programmes has been demonstrated in several studies. It is claimed that, in general, they have a similar impact in decreasing the glycaemic blood level of people with diabetes, increasing the understanding of diabetes by changing the perception of managing diabetes on a daily basis, and improving the life style of people with diabetes.

A multicentre cluster randomised controlled trial of the DESMOND programme by Davies et al. (2011) indicated there was a significant decrease in terms of HbA1c level of people with diabetes over a 12 month period, and there was some reduction in smoking behaviour and greater physical activity (self-reported) after 8 months. In another study, Skinner et al. (2006) found that after attending the DESMOND programme for 3 months, people with diabetes improved their understanding of the disease $(p<0.001)$; better understanding was associated with higher reported quality of life and better glycaemic control.

Keen, Duncan, McKillop-Smith, Evans, and Gold (2011) evaluated the DAFNE programme in a study involving 124 participants with type 1 diabetes. Using a pre and post-test design, they compared $\mathrm{HbA} 1 \mathrm{C}$ and the incidence of diabetes complications at baseline and 12 months following the programme. While the results showed no significant difference for $\operatorname{HbA1c}(p=0.123)$, there was significant reduction in diabetes complications $(p=0.039)$. The researchers indicated routine adoption of DAFNE might be beneficial for people with poorly controlled diabetes in terms of the reduction of $\mathrm{HbA} 1 \mathrm{C}$ and for emotional well-being, when highly motivated diabetes educators are available. It was recommended to further test the programme in other "real world" situations where the conditions were different to the context of the study (Keen et al., 2011).

The X-PERT programme was evaluated in a randomised controlled trial involving 314 participants in four community venues in the UK (Deakin et al., 2006). The study found the model played a significant role in improving glycaemic control $(\mathrm{HbA} 1 \mathrm{c})(p<0.001)$, reducing the use of medication, reducing body weight, $\mathrm{BMI}(p=0.001)$ and waist circumference, lowering total cholesterol $(p<0.001)$, increasing the intake of fruit and vegetables, and increasing diabetes knowledge $(p<0.001)$. The researchers suggested the effectiveness of the X-PERT model may be due to the theoretical 
model used, the skill and motivation of the educator, peer support and group-work, and goal setting (Deakin et al., 2006).

The exploration of qualitative aspects of structured education programmes showed that people with diabetes type 2 who were participating in the DESMOND programme in the UK had greater knowledge concerning identification and management of their disease (Ockleford, Shaw, Willars, \& Dixon-Woods, 2008). A similar result was found in the study by Murphy, Casey, Dinneen, Lawton, \& Brown (2011), where people with diabetes who attended the DAFNE programme claimed knowledge is an essential part of self-management and contributes to a sense of patient empowerment. Rankin et al. (2011) explored patients' experience in five centres in relation to attending the DAFNE programme, and also showed that people with diabetes type 1 felt empowered in terms of the flexible use in insulin therapy.

All the evidence above has mentioned the benefits of the implementation of structured education programmes. In all the studies, the programmes were implemented using a group-based approach and it is believed this type of method would be suitable for developing countries such as Indonesia where there are limited health care resources and systems. However, the studies did not provide information about how the programmes may be adapted in order to integrate them into other cultures. For a health education programme to meet the needs of people with a diversity of cultures, health status and conditions, experiences and ethnicities, health professionals involved in the programmes need to have cultural sensitivity and cultural competence (Brown et al., 2011; Hawthorne, Robles, Cannings-John, \& Edwards, 2008). This may require strategies to improve cultural competence of health professionals, in order to ensure effective interaction and transfer of health information and to prevent misunderstanding.

\subsection{Contextual considerations for Indonesia}

The three structured education models outlined above, $X$-PERT, DESMOND and DAFNE, have been successful in a western context; however, there are certain considerations for their adoption and utilisation in a culturally appropriate way in Indonesia. These considerations primarily relate to the feasibility and acceptability of the programme, which will be influenced by aspects such as mode of delivery, programme content, and interaction between health professionals and programme participants. These three aspects are discussed in the context of Indonesia in the following three subsections.

\subsection{Mode of delivery: group based education}

Chronic diseases, particularly diabetes, are not yet a priority in Indonesian government policy. As with other developing countries, Indonesia is still struggling to deal with communicable diseases, such as malaria, dengue fever and other infections (Kementrian, 2007). Although the government has acknowledged that there were an increasing number of people with diabetes in Indonesia, and it is predicted that this number will increase further in the coming years, there is still no significant national programme for dealing with the disease. The number of diabetes educators is still very low due to restricted funding to conduct diabetes educator training. Consequently, health and management information regarding diabetes is mainly delivered in an unstructured and unevaluated manner by health professionals with no specific training. Moreover, the disparity in the ratio between patients and health professionals also results in excessive workloads (Balitbang Depkes RI, 2013).

Considering these factors, it can be concluded that a group-based education programme would be most appropriate for the Indonesian context. Group-based education means that the educational session in the programme is mainly delivered to a group of patients with some provision one-on-one sessions. Compared to well-established diabetes education programmes (such as X-Pert, DESMOND and DAFNE), in Indonesia there would have to be a different number of patients in a group. The number of people in a group in the Indonesian context would likely be 12 to 15 due to the unbalanced ratio between health professionals and people with diabetes, rather than the six to ten which is common in western contexts (NICE, 2003). However, with larger group sizes, more patients will have the opportunity to access the programme. Choosing a group-based education programme would also provide other accessibility benefits as Indonesian people are collective in nature; patients would invite their friends who also experienced diabetes to join the group since they would be more comfortable in a familiar environment.

Another issue to be considered is how health professionals and patients would respond to a group based programme. Testing the feasibility of an Indonesian diabetes education programme would require introducing and implementing it in more than one Puskesmas, and the response to it would provide a better understanding on challenges and benefits of the programme. Some aspects that are relevant to choosing which Puskesmas should be involved include its accessibility by public transport, the number of patients with diabetes who live in the Puskesmas catchment area, and whether it would allow patients access to use public and private health insurance.

\subsection{Content of a health education programme}

Proposing and choosing a health education model that would suit the Indonesian community requires consideration of culture, ethnicity, ease of access and geographical issues. Indonesia has eastern cultural values and beliefs. Most people within an eastern culture have food preferences that are different to those in the west. For example, consumption of white steamed rice, poultry and meat is a challenge in dietary management for people with diabetes. Moreover, traditional views on food also present challenges in following a dietary regimen since at social gatherings large amounts of food are often served (Cha et al., 2012). Consideration of this issue requires that a health education programme provide information on diet based on adjustments to commonly eaten foods, and advice on how to manage diet on a daily basis 
and also on special occasions. This can be facilitated by using local resources that have been developed by experts in diabetes management in Indonesia (Soegondo, Soewondo, Suastika, Soetmadji, \& Tjokroprawiro, 2010).

Moreover, Indonesians' beliefs about health and healthy values will affect their perspective about any health education programme. Many Asians, particularly those in mainly Muslim countries such as Indonesia, believe that health is a result of self-cultivation. Humans are created by God and how they treat themselves will influence their health condition (Lundberg \& Thrakul, 2011). Providing information to people with diabetes on how to manage their disease would be more convincing to patients if health professionals related the information in a religious context. Another religious issue that needs to be taken into account is safe fasting during Ramadhan. Ramadhan is a holy month for Muslims during which adults are required to fast. An update of the DESMOND programme relating to Ramadhan provided training for health professionals and patient education sessions to raise awareness of the need for people with type 2 diabetes to fast safely. The information can be tailored to help manage diet and medication for people with diabetes who decide to fast during Ramadhan (The DESM Collaborative, 2008).

The last aspect that will have an impact on programme content is the use of traditional medicine. Most Indonesians believes that traditional medicine can cure several diseases, including diabetes (Soegondo et al., 2010). The use of traditional medicine as complementary therapy is acknowledged in modern diabetes treatment (Suyono, 2007). However, because of a lack information and misunderstanding around complementary therapies, most people with type 2 diabetes believe that it will be effective in lowering their blood glucose. Moreover, information provided by some manufacturers of complementary therapies implies that their products can cure diabetes (Obat traditional diabetes \& mellitus, 2013). Consequently, many people with diabetes believe therapies such as herbal medicine, stone and heat therapy would cure their disease, and thus ceased taking medication prescribed by health professionals. Thus, providing more comprehensive information on the use of complementary medicine as one of programme content by health professionals as being a significant advantage in reducing misuse and misunderstanding of traditional medicine.

\subsection{Interactive approach between health professionals and people with diabetes}

Health education programmes should have an interactive approach, including sharing of information between people with diabetes and health providers. Health education also involves human encounters where not only is knowledge transferred but there is also mutual understanding and respect (Green \& Kreuter, 2005). The fact that Indonesia was colonised by the Dutch for over 350 years has had an impact on how the Indonesian people think and interact. At times, health professionals' authority can dictate their clients' management of the condition. Helping health professionals adopt a new interactive style needs a comprehensive strategy. Health professionals must become active listeners, reduce their authoritarian approach, and regard people with diabetes as being the subject rather than an object. Therefore, a new way of delivering health education programmes to people with diabetes needs to be introduced to health professionals (Holmstorm \& Roing, 2009; Torres, Rozemberg, Amara, \& Bodstein, 2010).

Moreover, health education also needs to consider the perspective of people with diabetes and involve their families in managing the disease (Meetoo \& Gopaul, 2004). People with diabetes need to actively participate in the process, have adequate knowledge and skills, have a partnership with a health care provider, commit to the treatment and be tolerant of uncertainty. The presence of family and peers can help people with diabetes feel that their health condition is something that they can share with others. Thus, a health education programme can benefit not only people with diabetes, but also the wider community (Hill, 2006; Soewondo, 2011).

\subsection{Implications for the application of a diabetes education programme in Indonesia}

The exploration of established and well-structured diabetes education programmes worldwide provides strong evidence for how an Indonesian diabetes education programme should be conducted. Several points of structured education, such as the strategy and intervention of the programme, the teaching methods and materials, and human resources are aspects that need to be taken into account when a structured education programme is adopted in the Indonesian context. These points are essential considerations in a diabetes education programme in Indonesia that would respect the local culture.

Adopting a culturally relevant diabetes education programme in Indonesia provides a better foundation for its sustainability in future. Considering the characteristics of an ethnic and cultural background can assist in overcoming the limitations of implementing westernised diabetes education models in developing countries. It is important to identify what might be possible in the setting of a certain community and then to identify how programmes can be developed, implemented and disseminated in a way that will maximise their impact and effectiveness with respect to population health outcomes.

In conclusion, this paper explores several considerations that should be taken into account in developing diabetes education programmes that are feasible, acceptable and sustainable in a certain community. It highlights several factors that will play a pivotal role in the success of a diabetes education programme, such as the capability of human resources, health beliefs and the availability of local resources. Developing a programme that is culturally appropriate would help in terms of reducing challenges and increasing acceptance.

\section{Conflict of interest}

The authors declare no conflicts of interest to report. 


\section{Acknowledgements}

This paper is a part of doctoral study that was supported by the Directorate General for Higher Education, Indonesia. The study is being supervised in Australia.

\section{References}

Balitbang Depkes RI. (2013). Riset kesehatan dasar (RISKESDAS). Jakarta: Ministry of Health RI.

Brown, S. A., Garcia, A. A., Winter, M., Silva, L., Brown, A., \& Hanis, C. L. (2011). Integrating education, group support and case management for diabetic Hispanics. Ethnicity \& Disease, 21, 20-26.

Cha, E., Yang, K., Lee, J., Min, J., Kim, K. H., Dunbar, S. B., et al. (2012). Understanding cultural issues in the diabetes self-management behaviors of Korean immigrants. The Diabetes Educator, 38.

Davies, M. J., Heller, S., Skinner, T. C., Campbell, M., Carey, M. E., Cradock, S., et al. (2011). Effectiveness of the diabetes education and self management for ongoing and newly diagnosed (DESMOND) programme for people with newly diagnosed type 2 diabetes: Cluster randomised controlled trial. BMJ, $1-11$.

Deakin, T., Cade, J. E., Williams, R., \& Greenwood, D. C. (2006). Structured patient education: The diabetes X-PERT programme makes a difference. Diabetes Medicine, 23, 944-954.

Department of Health [DH], \& Diabetes UK. (2005). Structured patient education in diabetes. pp. 1-61. London: Department of Health (DH).

Fan, L., \& Sidani, S. (2009). Effectiveness of diabetes selfmanagement education intervention elements: A meta-analysis. Canadian Journal of Diabetes, 33, 18-26.

Glanz, K., \& Schwartz, M. D. (2008). Stress, coping and health behavior. In K. Glanz, B. K. Rimer, \& K. Viswanath (Eds.), Health behavior and health education theory, research and practice (4th ed., pp. 211-236). San Francisco: John Wiley \& Sons Inc.

Glanz, K., Rimmer, B. K., \& Viswanath, K. (2008). Health behavior and health education. San Francisco: Jossey-Bass a Wiley Imprint.

Green, L. W., \& Kreuter, M. W. (2005). Health program planning: An educational and ecological approach (4th ed.). Boston: McGraw Hill.

Hawthorne, K., Robles, Y., Cannings-John, R., \& Edwards, A. (2008). Culturally appropriate health education for type 2 diabetes mellitus in ethnic minority groups. The Cochrane Library.

Hill, J. (2006). Management of diabetes in South Asian communities in the UK. Nursing Standard, 20, 57-64.

Holmstorm, I., \& Roing, M. (2009). The relation between patient-centeredness and patient empowerment: A discussion on concepts. Patient Education and Counseling, 79, $167-172$.

IDF. (2013). IDF diabetes at las (6th ed.). Brussels: International Diabetes Federation.

Jarvis, J., Skinner, T. C., Carey, M. E., \& Davies, M. J. (2010). How can structured self-management patient education improve outcomes in people with type 2 diabetes? Diabetes, Obesity and Metabolism, 12, 12-19.

Keen, A. J. A., Duncan, E., McKillop-Smith, A., Evans, N. D., \& Gold, A. E. (2011). Dose Adjusment for Normal Eating (DAFNE) in routine clinical practice: Who benefits? Diabetic Medicine, 29, 670-676.

Kementrian Kesehatan Republik Indonesia. (2004). Depkes RI (Ed.), Kebijakan dasar Puskesmas (Vol. Kepmenkes no.128) (pp. 1-28). Jakarta: Depkes RI.
Kementrian Kesehatan Republik Indonesia. (2007). . Program kerja ditjen penyehatan lingkungan dan pemberantasan penyakit tidak menular (Vol. 2012) Jakarta: Depkes RI.

Kementrian Kesehatan Republik Indonesia. (2011). Profil Kesehatan Indonesia Tahun 2010. pp. 1-194. Jakarta: Depkes RI.

Kementrian Kesehatan Republik Indonesia. (2012). Data dasar Puskesmas. Jakarta: Departemen Kesehatan RI.

Kementrian Kesehatan Republik Indonesia. (2014). . Diabetes Melitus Penyebab Kematian Nomor 6 di Dunia: Kemenkes Tawarkan Solusi CERDIK Melalui Posbindu (Vol. 2014) Jakarta: Kemenkes RI.

Lundberg, P. C., \& Thrakul, S. (2011). Diabetes type 2 selfmanagement among Thai Muslim women. Journal of Nursing and Healthcare of Chronic Illness, 3, 52-60.

Meetoo, D., \& Gopaul, H. (2004). Empowerment: Giving power to people with diabetes. Diabetes \& Primary Care, 6, 164-170.

Murphy, K., Casey, D., Dinneen, D., Lawton, J., \& Brown, F. (2011). Participant's perceptions of the factors that influence Diabetes Self-Management Following a Structured Education (DAFNE) programme. Journal of Clinical Nursing, 20, $1282-1292$.

NDEP. (2011). Diabetes prevention and lifelong management. In Redesigning the health care team. Washington: NIH Publication.

NDSS. (2014). . Support services (Vol. 2014) Australia: Diabetes Australia.

Neraca. (2013). . Spesialis diabetes minim, pasien sulit konsultasi, Jakarta (Vol. 2013)

NICE. (2003). Guidance on the use of patient-education models for diabetes technology appraisal 60. London, UK: National Institute for Clinical Excellence.

Obat traditional diabetes mellitus. (2013). . Obat traditional diabetes mellitus (Vol. 2014).

Ockleford, E., Shaw, R. L., Willars, J., \& Dixon-Woods, M. (2008). Education and self-management for people newly diagnosed with type 2 diabetes: A qualitative study of patients' views. Chronic Illness, 4, 28-37.

Rankin, D., Cooke, D. D., Clark, M., Hellert, S., Elliot, J., \& Lawton, J. (2011). How and why do patients with type 1 diabetes sustain their use of flexible intensive insulin therapy? A qualitative longitudinal investigation of patients' self-management practices following attendance at a Dose Adjustment for Normal Eating (DAFNE) course. Diabetic Medicine, 28, 532-538.

Skinner, T. C., Carey, M. E., Cradock, S., Daly, H., Davies, M. J., Doherty, Y., et al. (2006). Diabetes education and selfmanagement for ongoing and newly diagnosed (DESMOND): Process modelling of pilot study. Patient Education and Counseling, 64, 369-377.

Soegondo, S., Soewondo, P., Suastika, K., Soetmadji, D., \& Tjokroprawiro, A. (2010). Buku Panduan Penatalaksanaan Diabetes Mellitus di Layanan Kesehatan Primer di Indonesia. Jakarta: fakultas Kedokteran Universitas Indonesia.

Soewondo, P. (2011). Current practice in the management of type 2 diabetes in Indonesia: Results from the international diabetes management practices study (IDMPS). Journal of Indonesian Medical Association, 61, 474-480.

Soewondo, P., Ferrario, A., \& Tahapary, D. L. (2013). Challenges in diabetes management in Indonesia: A literature review. Globalization and Health, 9.

Suyono, S. (2007). Penatalaksanaan diabetes mellitus terpadu (integrated management of diabetes mellitus). Jakarta: Faculty of Medicine University of Indonesia.

The DESMOND Collaborative. (2008). . A safer Ramadhan kit: 3 wars to raise awareness for fasting safely (Vol. 2014) United Kingdom: DESMOND Collaborative.

Torres, H. C., Rozemberg, B., Amara, M. A., \& Bodstein, R. C. (2010). Perceptions of primary healthcare professional towards their role in type 2 diabetes mellitus patient education in Brazil. BioMed Central, 10, 1471-2458. 
WHO. (1998). Health promotion glossary. Geneva: World Health Organization.

WHO. (2011). Noncommunicable (NCD) diseases country profiles. Paris, France: World Health Organization.
Widyahening, I. S., \& Soewondo, P. (2012). Capacity for management of type 2 diabetes mellitus (T2DM) in primary health centres in Indonesia. Journal of Indonesia Medical Association, 62, 439-443. 